\title{
Harmonic sluicing: Which remnant/correlate pairs work and why *
}

\author{
Matthew Barros \\ Rutgers University
}

\begin{abstract}
I claim that two generalizations about sluicing in the recent literature are epiphenomenal, emerging from the interaction of independent properties of sluicing and answerhood. The primary focus is on the generalization in Dayal \& Schwarzschild 2010, dubbed Antecedent-Correlate Harmony (ACH). The empirical pattern is shown to follow from how the semantics of Wh-phrases and correlates interact with Barker's (in press) Answer Ban generalization, where the antecedent cannot be an answer to the sluiced question. In the latter part of the paper, I shift focus from ACH to the Answer Ban and show how the Answer Ban fills a previously unnoticed gap in Romero's (1998) empirical coverage of Inheritance of Content effects in sluicing. The Answer Ban is, in turn, shown to follow straightforwardly from the recent semantic condition on sluicing proposed in AnderBois 2011.
\end{abstract}

Keywords: Sluicing, Kinds, Answerhood, Taxonomic Hierarchies

\section{Introduction and background}

Sluicing is ellipsis in a Wh-question, leaving the Wh-phrase overt (Ross 1969). The Wh-phrase is called the remnant. Remnants typically correspond to an XP in the antecedent called the correlate. Sluicing is a form of surface anaphora in Hankamer \& Sag's (1976) sense, thus requiring a linguistic antecedent for licensing. In (1), the antecedent is the left conjunct 'Jack talked to someone,' the remnant is 'who,' and the correlate is 'someone' (strikethrough represents elided material).

(1) Jack talked to someone, but Fred doesn't know who Jack talked to $t_{1}$.

I focus here on deriving the generalization in Dayal \& Schwarzschild 2010 (henceforth D\&S) dubbed Antecedent Correlate Harmony (henceforth ACH), below:

(2) ACH: The remnant and correlate agree on the presence/absence of a contentful head noun.

* Many thanks to Ken Safir, Mark Baker, Roger Schwarzschild, Chris Barker, Scott AnderBois, and the audiences at MACSIM II, CUNY Syntax Supper, the Semantics Research Group at Rutgers, and SALT 23 for many helpful comments. Special thanks goes to Veneeta Dayal for guidance at every stage of this project's development. Any mistakes herein are my own. 
$\mathrm{ACH}$ is motivated in D\&S by the data in (3); if the correlate is an indefinite pronoun, the remnant must lack an NP complement, whereas an indefinite description requires a remnant with an NP (remnants and correlates underlined).

a. * Joan ate a donut. Fred doesn't know what.

b. Joan ate something. Fred doesn't know what.

c. * Joan ate something. Fred doesn't know which donut.

d. Joan ate a donut. Fred doesn't know which donut.

First, I claim that only a subset of ACH data follows from sluicing-specific considerations (the $\mathrm{ACH}$ paradigm should not receive a unified account). Second, sluicingspecific ACH effects follow from the interaction between the semantics of correlate NPs, remnants, and the constraint in (4), proposed by Barker (in press).

(4) Answer Ban: The antecedent cannot be an answer to the sluiced question. ${ }^{1}$

In the latter part of the paper, I focus on the Answer Ban itself. First, I highlight how the Answer Ban fills an explanatory gap in the account of sluicing given in Romero 1998 (often adopted in more recent literature), and then show how the Answer Ban follows from the semantic condition on sluicing proposed in AnderBois 2011.

\section{Narrowing the domain of inquiry}

\subsection{ACH violations can be split into two classes}

D\&S takes ACH to be a sluicing-specific generalization, which is supposed to capture the entire pattern illustrated in (3). In this section, I show that the arguments in D\&S for ACH-as-sluicing-specific only apply to a subset of the data in (3). I take this as an indication that $\mathrm{ACH}$ is not a unified phenomenon; there must be a sluicing-specific account, capturing that data in (3) for which the arguments in D\&S do go through, and a non-sluicing-specific account, capturing the rest of the data.

Before proceeding, it is useful to make a distinction between $\mathrm{ACH}$ violation types: bare violations are where the remnant is a simple Wh-phrase and the correlate has a contentful NP (e.g. (3a)); contentful violations are those where the remnant has an NP, but the correlate is an indefinite pronoun (e.g. (3c)). The argument given in D\&S for why ACH is sluicing-specific only considers bare violations.

Their argument is as follows. If ACH were not sluicing-specific, it should apply to both sluices and their corresponding pre-sluices (the non-elliptical alternant of the sluiced question). D\&S shows that once confounds are controlled for, this prediction is not borne out, supporting the conclusion that $\mathrm{ACH}$ is sluicing-specific.

1 Barker's formulation is couched in terms of inquisitive semantics (Groenendijk \& Roelofsen 2009), I've modified it since I will not be using the inquisitive semantics framework here. 
Harmonic sluicing

First, note that since the $\mathrm{ACH}$ violations in (5) are out, the notion that $\mathrm{ACH}$ is not sluicing-specific is supported, since the judgement for the pre-sluice is the same as the judgement for the sluice. It follows that whatever account is given for the judgement in (5b) should extend straightforwardly to the judgement in (5a).

a. * Joan ate a donut, but I don't know what.

b. * Joan ate a donut, but I don't know what she ate.

However, as noted in D\&S, what appears to be an $\mathrm{ACH}$ effect in (5b) follows from the felicity conditions on denying knowledge of a question (see Romero 1998). In (5b), the speaker has committed themselves, in uttering the antecedent, to having an answer to the question 'what she ate,' so that they cannot then deny knowledge of the question. Switching from a $1^{\text {st }}$ to $3^{\text {rd }}$ person subject controls for this, avoiding the inconsistency in (5b) (see (6b)); however, the sluiced version does not improve (as shown in (6a)), supporting the notion that ACH is sluicing-specific.

a. * Joan ate a donut, but Fred doesn't know what.

b. Joan ate a donut, but Fred doesn't know what she ate.

Importantly, the same argument does not extend to contentful violations. In (7), switching to a $3^{r d}$ person subject neither improves the pre-sluice nor the sluice.

a. * Jack ate something. $\{$ I don't/Sally doesn't $\}$ know which donut.

b. * Jack ate something. \{I don't/Sally doesn't $\}$ know which donut he ate.

Contentful violations call for a non-sluicing-specific story, as the pattern observed in sluicing is detected in its absence; there is sluicing-specific $\mathrm{ACH}$, pertaining only to bare violations, and non-sluicing-specific $\mathrm{ACH}$, pertaining to contentful violations. In this paper, I focus only on sluicing-specific violations (and thus, bare violations), leaving an account of non-sluicing-specific violations to future work. ${ }^{2}$

2 A plausible lead in accounting for the paradigm in (7) is to consider the semantic and pragmatic requirements of 'which,' which requires a salient set of alternatives in the discourse; the antecedents in (7) fail to introduce such a set. In support of an account along these lines, consider (i), below; here the antecedent contains lexical material which implicates the requisite set of entities for licensing 'which' (e.g. the verb 'firing' suggests a workplace with a set of employees):

(i) Sally fired someone, guess which employee she fired.

Importantly, in (i), both the sluice and the pre-sluice are acceptable, in support of the non-sluicingspecific nature of $\mathrm{ACH}$ effects involving contentful violations. 
Matthew Barros

\subsection{Further sharpening the data}

Dayal \& Schwarzschild (2010) probe the animate/inanimate distinction in remnants (i.e. 'who' vs. 'what'), though they do not do so extensively, since their primary interests lie elsewhere. Their empirical claim is that bare $\mathrm{ACH}$ violations with 'what' are unacceptable (see (8a)), though violations with 'who' are, though sometimes 'exactly'-modification of the remnant is required (compare (8b) and (8c)).

a. * Joan ate a donut. Fred doesn't know what (exactly).

b. Linguists go to those conferences. Fred doesn't know who *(exactly).

c. Sally met a phonologist. Fred doesn't know who (exactly).

In fact, the data with inanimates are more nuanced; first, acceptable violations are possible with 'what,' just as with 'who,' and second, just as with 'who,' sometimes 'exactly'-modification of the inanimate remnant is required. The relevant data can be split into three classes: (a) irredeemable violations, which are unacceptable regardless of 'exactly'-modification (e.g. (9)); (b) redeemable violations, which are unacceptable without 'exactly'-modification (e.g. (10)); and (c) ACH defiant violations, which are good regardless of 'exactly'-modification (e.g. (11)).

a. * Jack had a profiterole, but Fred doesn't know what exactly.

b. * Jack ordered an éclair, but Fred doesn't know what exactly.

c. * Jack got a cat, but Fred doesn't know what exactly.

(10) a. Jack had a Cajun dish, but Sally doesn't know what *(exactly).

b. Jack ordered a pastry, but Sally doesn't know what *(exactly).

c. Jack drives a foreign car, but Fred doesn't know what *(exactly).

(11) a. Jack had a drink, but Sally can't recall what (exactly).

b. Jack ordered food, but Sally doesn't know what (exactly).

c. Jack ordered an appetizer, but Sally can't recall what (exactly).

What differentiates each class seems to be, roughly, the degree of "specificity" of the NP choice in the correlate. Compare, for example, (9b), (10b), and (11b), which differ only in the choice of correlate NP; 'éclair' is more specific than 'pastry,' which, in turn, is more specific than 'food'; the less specific a correlate's NP, the more acceptable an inanimate bare $\mathrm{ACH}$ violation becomes. ${ }^{3}$

3 There is a high degree of interspeaker variation, for a given noun choice in the correlate, whether an irredeemable, redeemable or defiant $\mathrm{ACH}$ violations results. Data collection in this study was carried out informally, that is by asking native English speaking linguists whether they accepted a given string. While all speakers accepted 'food' as ACH defiant, some found 'Cajun dish' "less redeemable" than 'foreign car', for instance. The data reported here reflects dominant tendencies in judgement patterns (accounting for the variation is beyond the scope of this paper). 
My basic claim is that unacceptability in bare violations results from a violation of Barker's (in press) Answer Ban (see (4)); the antecedents in unacceptable violations count as answers to the sluiced question. More specific correlates render the antecedent an answer to the sluiced Q, but not less specific correlates. The relevant notion of specificity can be captured with reference to taxonomic hierarchies; less specific nouns are higher on the hierarchy than more specific nouns. A plausible hierarchy for some of the nouns in (9)-(11) is given below:

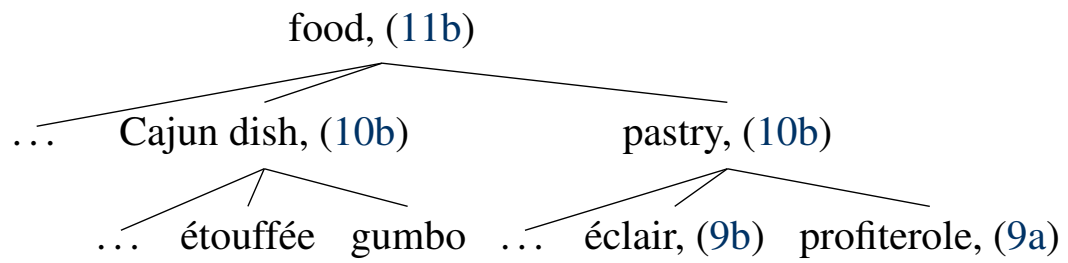

Before proceeding, I provide a test for determining when the Answer Ban is behind the unacceptability of bare violations. A distinction crucial to the account defended here lies in how we understand the notion of answerhood as it pertains, on the one hand, to the Answer Ban, and, on the other, a more general notion.

The felicity conditions on asking, or denying knowledge of $\mathrm{Q}$, are sensitive to answerhood (call them Q-felicity conditions). To ask, or deny knowledge of Q, one must not know the answer to Q. This is why (13a) and (13b) are inconsistent.

(13) a. Sally met Jack, but \{Sally doesn't/\#I don't $\}$ know who she met.

b. A (to B): Sally met Jack. B: \#Who did she meet?

c. * Sally met Jack, but Sally doesn't know who.

As noted in D\&S in defense of the claim that $\mathrm{ACH}$ is sluicing-specific, switching to a $3^{\text {rd }}$ person subject in (13a) fixes the inconsistency. In D\&S, such data are taken as evidence that $\mathrm{ACH}$ is not sensitive to answerhood, since, as examples like (13c) show, unacceptability persists despite a $3^{\text {rd }}$ person subject, which fixes (13a).

Here, I assume it is precisely answerhood at stake (pace Dayal \& Schwarzschild (2010)). Importantly, the Answer Ban only checks whether the antecedent is an answer to the constituent question $\mathrm{CP}$; the grammatical person of the matrix subject is irrelevant. Since the antecedent in both (13a) and (13c) counts as an answer to 'who she met,' the Answer Ban blocks sluicing. Second, the Answer Ban is sluicing-specific, which is why it is not active in the pre-sluice for (13c) in (13a).

This gives us a diagnostic for the Answer Ban; while the Answer Ban makes no reference to Q-felicity conditions, we can use these conditions to test for answerhood. We predict that for any Answer Ban violation, we can reproduce the patterns in (13); a pre-sluice with a $1^{\text {st }}$ person matrix subject should be out, but not a $3^{\text {rd }}$ 
person subject (as in (13a)), and having "speaker B" ask the sluiced CP in response to the antecedent, as in (13b), should violate Q-felicity conditions.

This much supports that the Answer Ban is behind the acceptability patterns observed in (9-11); the pattern in (13) can be reproduced, with variations as predicted for irredeemable (see (14)), redeemable (see (15)), and defiant cases (see (16)):

(14) a. She had a donut, but $\{$ Jack doesn't/\#I don't $\}$ know what she had.

b. A: She had a donut. B: \#What did she have?

c. * She had a donut, but Jack doesn't know what.

(15) a. i. She had a Cajun dish, but Jack doesn't know (exactly) what she had. ii. ... but I don't know \#(exactly) what she had.

b. A: She had a Cajun dish. B: What \#(exactly) did she have?

c. She had a Cajun dish, but Jack doesn't know what *(exactly).

(16) a. She had some food, but $\{$ Jack doesn't/I don't $\}$ know what (exactly).

b. A: She had some food. B: What did she have?

c. She had some food, but Jack doesn't know what.

In short, antecedents in irredeemable cases always count as answers to the sluiced question, only count as such in redeemable cases in the absence of 'exactly'-modification of the remnant, and never count as such in ACH defiant cases.

In the following, I focus on how different NP choices in (9-11) interact with answerhood, the role of 'exactly' in redeeming redeemable cases, and why acceptable bare violations with animates are more freely available than with inanimates. This will be shown to follow from a difference in the semantics of 'what' and 'who.'

\section{A semantics for questions, answers, and bare remnants}

I adopt a Hamblin 1973/Karttunen 1977 semantics for questions: Qs denote the set of possible answers to Q, and Wh-phrases are existential quantifiers. For the question 'who left' in a model with just Jack and Bill, we get a set like that in (17).

$$
\begin{aligned}
& \llbracket \text { who left } \rrbracket=\lambda \mathrm{p} \exists \mathrm{x}\left[\operatorname{human}(\mathrm{x}) \wedge \mathrm{p}={ }^{\wedge} \operatorname{left}(\mathrm{x})\right] \\
& =\left\{{ }^{\wedge} \operatorname{left}(\text { Jack }),{ }^{\wedge} \operatorname{left}(\text { Bill }),{ }^{\wedge} \operatorname{left}(\text { Bill }+ \text { Jack })\right\}
\end{aligned}
$$

Additionally, I follow Heim (1987) in assuming that 'what' quantifies over kind level entities. Some evidence for this comes from 'there'-existential constructions; kind-denoting NPs behave as weak in post-copular position in existential constructions (adopting Milsark's (1977) terminology) (see (18a)). As Heim (1987) notes, a 'what'-trace also behaves as weak in the same position: 
Harmonic sluicing

(18) a. Thee is every *(kind of) linguist in Austin.

b. What is there in Austin?

c. * Who is there in Austin?

Dayal (in prep) also notes that ' $w$ hat $N_{\text {animate' }}$ prefers a 'kind of' reading:

a. \{what/\#which $\}$ man would do such a thing? ('what kind of man ...')

b. $\{$ which/\#what $\}$ student is she talking to?

Additionally, bare 'what' needs a choice between kinds (see (20)) where a choice between object-level entities is all that is required for 'which.' I indicate 'what"s sortal restriction to kinds with a superscript $k$ on the variable in (21).

(20) Context: There are three identical mugs before you, each with coffee in them.

\{which/\#what $\}$ was yours again?

$\llbracket$ what $\rrbracket=\lambda \mathrm{Q} \exists \mathrm{x}^{\mathrm{k}}\left[\right.$ Non-human $\left.\left(\mathrm{x}^{\mathrm{k}}\right) \wedge \mathrm{Q}\left(\mathrm{x}^{\mathrm{k}}\right)\right]$

For kind-level arguments with object-level predicates, I adopt derived kind predication (DKP), in Chierchia 1998:

(22) DKP: If $\mathrm{P}$ applies to objects, and $\mathrm{x}^{\mathrm{k}}$ denotes a kind:

$$
\mathrm{P}\left(\mathrm{x}^{\mathrm{k}}\right)=\exists \mathrm{y}^{\mathrm{o}}\left[\mathrm{x}^{\mathrm{k}}\left(\mathrm{y}^{\mathrm{o}}\right) \wedge \mathrm{P}\left(\mathrm{y}^{\mathrm{o}}\right)\right]
$$

A question like 'what broke?,' then, gets the meaning in (23):

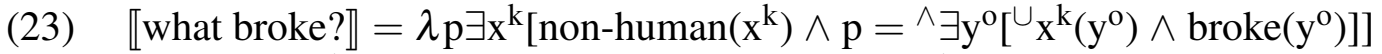
$\left\{\wedge \exists \mathrm{y}^{\mathrm{o}}\left[\mathrm{Vase}^{\mathrm{k}}\left(\mathrm{y}^{\mathrm{o}}\right) \wedge \operatorname{broke}\left(\mathrm{y}^{\mathrm{o}}\right)\right],{ }^{\wedge} \exists \mathrm{y}^{\mathrm{o}}\left[{ }^{\cup} \operatorname{wineglass}^{\mathrm{k}}\left(\mathrm{y}^{\mathrm{o}}\right) \wedge \operatorname{broke}\left(\mathrm{y}^{\mathrm{o}}\right)\right], \ldots\right\}$ or $\{\wedge$ a vase broke, $\wedge$ a wineglass broke, ... $\}$

For answers, I adopt Dayal's (1996) answerhood operator, Ans, which selects the true proposition that entails all other true propositions in the question meaning:

$$
\operatorname{Ans}(\mathbf{Q})=\imath \mathrm{p}\left[\mathrm{Q}(\mathrm{p}) \wedge{ }^{\vee} \mathrm{p} \wedge \forall \mathrm{p}^{\prime} \in \mathrm{Q}\left[\left[^{\vee} \mathrm{p}^{\prime} \wedge \mathrm{Q}\left(\mathrm{p}^{\prime}\right)\right] \rightarrow \mathrm{p} \subseteq \mathrm{p}^{\prime}\right]\right]
$$

With this machinery, the Answer Ban is violated whenever the antecedent entails Ans(Q). I proceed to show how these assumptions work with inanimates.

\section{The three different kinds of inanimate correlate}

\subsection{The Basic/Super-Basic level distinction}

I focus first on irredeemable cases. Recalling the structure in (12), each 'level of specificity' in (12) maps to a different pattern of acceptability: 
Matthew Barros

(25)

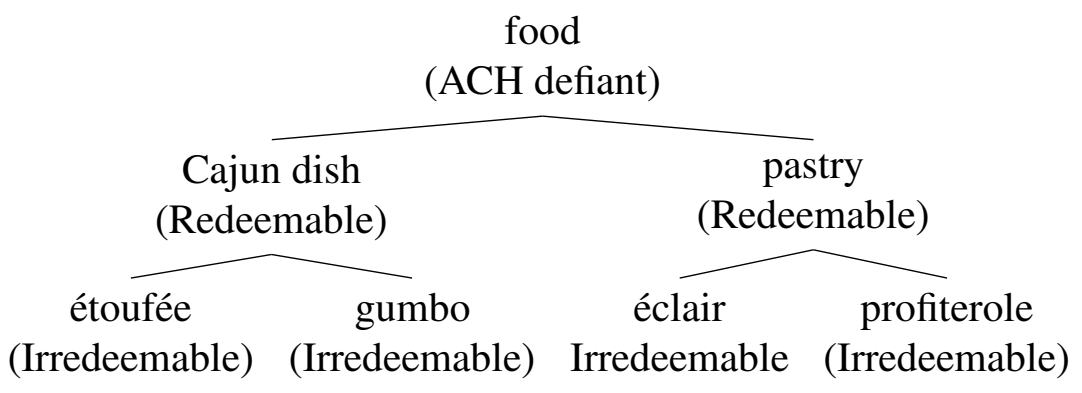

The irredeemable level corresponds to what have been called basic level (BL) nouns in the literature (Brown 1958, Cruse 1977, Rosch, Mervis, Gray, Johnson \& BoyesBraem 1976, Rosch 1978, Heller \& Wolter 2008).

An NP corresponding to any level of specificity may appropriately apply to a given object, but the choice of level of specificity is not random; a noun corresponding to the BL is privileged. For instance, to take an example from Cruse 1977, if you own a cat, aside from the cat's name, the NP [NP cat ] is most suitable in (26): $:^{4}$

I'm taking the $\{\mathrm{cat} / \#$ mammal/\#American longhair $\}$ to the vet.

BL nouns like ' $c a t$ ' constitute, in some intuitive sense, a 'neutral' level of specificity (adopting Cruse's (1977) terminology). BL nouns are more frequently used to refer to objects than non-BL nouns, and BL nouns have been claimed to be appropriate for classifying objects in a relevant way in "most contexts."

I do not concern myself here with why the BL is privileged; following Cruse (1977), the factors that determine whether a noun corresponds to a basic or nonbasic level of specificity are arguably non-linguistic. Nonetheless, a noun's BL status has linguistic consequences. One example of this comes from work on Whever free relatives (see Dayal 1997, Heller \& Wolter 2008); it is only felicitous to use a Wh-ever free relative if you cannot identify its referent at the basic level.

The underlined clauses in (53) have an argument corresponding to various levels of specificity; if the correlate nouns in the irredeemable cases are BL Ns, we expect to see the pattern in (53). Correlate nouns in irredeemable cases will block Wh-ever free relatives, whereas non-BL nouns introduce sufficient indeterminacy.
a. Jack prepared some food. Whatever it was, he really enjoyed it.
b. Jack ordered a Cajun dish. Whatever it was, he really enjoyed it.
c. * Jack ordered a profiterole. Whatever it was, he really enjoyed it.

\footnotetext{
4 Worth noting is that any of the descriptions in (26) would satisfy the conditions on licensing the definite article (i.e. would serve to uniquely identify a familiar referent in the context of utterance), so that infelicity of non-BL nouns in (26) cannot follow from the failure to license the definite.
} 
Harmonic sluicing

Another difference between BL correlates and less specific correlates (super basic level or SBL), is that SBL correlates allow for a subkinds reading. This can be detected in (28-29); access to the sub-kinds reading for SBL 'Cajun dish' allows those sub-kinds to be counted. BL nouns (e.g. 'donut') do not seem to have a subkinds reading, as only the object-level instantiations of donuts may be counted: 5

(28) Context: There are 9 bowls on the table, three of them have jambalaya in them, three, gumbo, and three, boudin.

a. Count the number of Cajun dishes on the table.

i. Three. (Three kinds of Cajun dishes)

ii. Nine. (Nine object-level Cajun dishes)

(29) Context: There are 9 donuts on the table, three of them are glazed, three of them are chocolate, and three of them are jelly-filled.

a. Count the number of donuts on the table.

i. * Three. (Three kinds of donuts)

ii. Nine. (Nine object-level donuts)

Another way of teasing out the sub-kinds reading in SBL nouns is as in (30). SBL nouns are ambiguous between a kinds reading, a sub-kinds reading, and an object level reading (e.g. 'Jack dropped a pastry on the floor'). The object level reading is implausible for a direct object of a verb like 'prepare,' or 'bake,' in the context in (30). Thus, (30) is only ambiguous between (30a) and (30b):

(30) Jack knows how to prepare a Cajun dish.

a. Jack knows, in general, how to prepare Cajun dishes. (Kind reading)

b. He knows how to prepare, for instance, jambalaya. (Sub-kinds)

c. \# He knows how to prepare the jambalaya Bill ate on Tuesday. (Object)

We can force a specific, sub-kinds reading in (30) by modifying 'Cajun dish' with 'certain' ('a certain Cajun dish'). This makes (30) unambiguous, only having the reading in (30b). However, disambiguation by 'certain' is not possible with a BL noun, which follows if the BL noun lacks the sub-kinds reading; (31) only has the reading in (31a), and modification by 'certain' only gives the implausible reading where Jack knows how to bake some actual individual donut.

Jack knows how to bake a (\#certain) donut.

5 It is arguably access to the (non-singleton) sub-kinds reading for the SBL nouns in (53) which introduces the indeterminacy required to license Wh-ever, assuming those sub-kinds include kinds at a basic level of specificity. 
a. Jack knows, in general, how to bake donuts. (Kind reading)

b. He knows how to bake a glazed donut. (Sub-kinds unavailable)

c. \# He knows how to bake the donut on the table. (Object)

\subsection{Sluicing with BL/SBL correlates}

This difference in the accessibility of a sub-kinds reading between SBL and BL nouns plays a central role in capturing the distinctions in (9-11). Following Krifka, Pelletier, Carlson, ter Meulen, Link \& Chierchia 1995, and Dayal 2004, Ns are ambiguous between denoting properties of kinds or object level entities. As mentioned in $\S 4.1$, SBL nouns are three ways ambiguous, and BL Ns only two ways.

SBL nouns have a property of kinds denotation (the singleton set with the kind as member), a property of sub-kinds denotation (the non-singleton set of the subkinds), and a property of objects denotation (the set of instantiations of the kind, differentiated here with numerical subscripts). BL nouns like 'donut,' on the other hand, have only the kind and object level denotations.
a. $\llbracket$ Cajun dish ${ }^{\text {kind }} \rrbracket=\left\{\right.$ Cajun $\left.\operatorname{dish}^{\mathrm{k}}\right\}$
b. $\llbracket$ Cajun dish ${ }^{\text {sub-kinds }} \rrbracket=\left\{\right.$ jambalaya $^{\mathrm{k}}$, boudin $^{\mathrm{k}}$, étoufée $\left.{ }^{\mathrm{k}}, \ldots\right\}$
c. $\llbracket$ Cajun dish ${ }^{\text {objects }} \rrbracket=\left\{\right.$ Cajun $\operatorname{dish}_{1}^{o}$, Cajun $\left.\operatorname{dish}_{2}^{o}, \ldots\right\}$
a. $\llbracket$ donut ${ }^{\text {kind }} \rrbracket=\left\{\right.$ donut $\left.^{\mathrm{k}}\right\}$
b. $\llbracket$ donut $^{\text {objects }} \rrbracket=\left\{\right.$ donut $_{1}^{\mathrm{o}}$, donut $\left.{ }_{2}^{\mathrm{o}}, \ldots\right\}$

This difference is insufficient to capture the facts in (9-11); we must also appeal to domain restriction in questions (specifically, sluiced Qs). As Chung, Ladusaw \& McCloskey (1995) note, remnants in sluices inherit the restriction of the correlate (a phenomenon dubbed Inheritance of Content). In (34), for instance, the sluiced Q only has a reading where Fred doesn't know which sort of Cajun dish Jack ordered. The pre-sluice in (35), however, is ambiguous between the indicated readings.

(34) Jack ordered a Cajun dish, but Fred doesn't know what exactly.

a. = Fred doesn't know what (Cajun dish) Jack ordered.

b. $\neq$ Fred doesn't know what (food) Jack ordered.

(35) Jack ordered a Cajun dish, but Fred doesn't know exactly what he ordered. (No obligatory Inheritance of Content, either (34a) or (34b) are possible)

Following Romero (1998), I model Inheritance of Content as domain restriction on the remnant. For domain restriction, I adopt a property-type variable $\mathrm{R}$ $\mathrm{i},\langle\mathrm{e}, \mathrm{t}\rangle$, freely available as an NP modifier, which may receive its value from a salient 
Harmonic sluicing

property (Bach \& Cooper 1978, von Fintel 1994, Heim \& Kratzer 1998). In sluicing, the correlate renders its NP's property salient, supplying the value for R in the remnant. Inheritance of Content, with the semantics of correlates and remnants, will get us violations of the Answer Ban when we need them, and not otherwise.

\subsubsection{Sluicing with SBL correlates (redeemable violations)}

For inanimate bare violations with 'what' as a remnant, there are two property-ofkinds denotations which may be inherited: the property of kinds and of sub-kinds denotations. ${ }^{6}$ The property of kinds violates the Answer Ban:

Jack ordered a Cajun dish, but I don't know what *(exactly).

«what Jack ordered $\rrbracket=$

$\lambda \mathrm{p} \exists \mathrm{x}^{\mathrm{k}}\left[\right.$ non-human $\left(\mathrm{x}^{\mathrm{k}}\right) \wedge$ Cajun $\left.\operatorname{dish}{ }^{\mathrm{kinds}}\left(\mathrm{x}^{\mathrm{k}}\right) \wedge \mathrm{p}={ }^{\wedge} \exists \mathrm{y}^{\mathrm{o}}\left[{ }^{\cup} \mathrm{x}^{\mathrm{k}}\left(\mathrm{y}^{\mathrm{o}}\right) \wedge \operatorname{ordered}\left(\operatorname{Jack}, \mathrm{y}^{\mathrm{o}}\right)\right]\right]$

$=\left\{\wedge \exists \mathrm{y}^{\mathrm{o}}\left[{ }^{\cup}\right.\right.$ Cajun $\operatorname{dish}^{\mathrm{k}}\left(\mathrm{y}^{\mathrm{o}}\right) \wedge \operatorname{ordered}\left(\right.$ Jack, $\left.\left.\left.\mathrm{y}^{\mathrm{o}}\right)\right]\right\}$

$\operatorname{Ans}(\mathrm{Q})={ }^{\wedge} \exists \mathrm{y}^{\mathrm{o}}\left[{ }^{\cup} \operatorname{Cajun} \operatorname{dish}^{\mathrm{k}}\left(\mathrm{y}^{\mathrm{o}}\right) \wedge \operatorname{ordered}\left(\mathrm{Jack}, \mathrm{y}^{\mathrm{o}}\right)\right]$

Since the antecedent entails $\operatorname{Ans}(\mathrm{Q})$, the Answer Ban is violated. Inheriting the property of sub-kinds would work as the antecedent does not entail Ans(Q).

«what Jack ordered $\rrbracket=$

$\lambda \mathrm{p} \exists \mathrm{x}^{\mathrm{k}}\left[\right.$ non-human $\left(\mathrm{x}^{\mathrm{k}}\right) \wedge$ Cajun dish $\left.{ }^{\text {sub-kinds }}\left(\mathrm{x}^{\mathrm{k}}\right) \wedge \mathrm{p}={ }^{\wedge} \exists \mathrm{y}^{\mathrm{o}}\left[\mathrm{x}^{\mathrm{k}}\left(\mathrm{y}^{\mathrm{o}}\right) \wedge \operatorname{ordered}\left(\operatorname{Jack}, \mathrm{y}^{\mathrm{o}}\right)\right]\right]$

$=\left\{\wedge \exists \mathrm{y}^{\mathrm{o}}\left[\operatorname{gumbo}^{\mathrm{k}}\left(\mathrm{y}^{\mathrm{o}}\right) \wedge \operatorname{ordered}\left(\operatorname{Jack}, \mathrm{y}^{\mathrm{o}}\right)\right]\right.$,

$\wedge \exists \mathrm{y}^{\mathrm{o}}\left[{ }^{\cup}\right.$ jambalaya $\left.\left.^{\mathrm{k}}\left(\mathrm{y}^{\mathrm{o}}\right) \wedge \operatorname{ordered}\left(\mathrm{Jack}, \mathrm{y}^{\mathrm{o}}\right)\right], \ldots\right\}$

$\operatorname{Ans}(\mathrm{Q})={ }^{\wedge} \exists \mathrm{y}^{\mathrm{o}}\left[{ }^{\cup} \operatorname{gumbo}^{\mathrm{k}}\left(\mathrm{y}^{\mathrm{o}}\right) \wedge \operatorname{ordered}\left(\mathrm{Jack}, \mathrm{y}^{\mathrm{o}}\right)\right]$

However, recall that 'Cajun dish' corresponds to the redeemable class of ACH violations, and requires 'exactly'-modification. I assume this is because 'exactly'modification is needed to access the sub-kinds reading for SBL nouns.

I propose a relevance implicature to capture this; if a more specific level than SBL were relevant in a given discourse, the speaker would choose a more specific noun in the correlate. Antecedents are assertions, and (following Roberts (1996) inter alia), assertions can be seen as answers to implicit questions. In a given discourse, different levels of specificity may be more or less relevant:

A: What did Jack order?

B: A Cajun dish (Fine at a food court, \# at a Cajun restaurant)

Sluicing contexts differ from those in (38) in having an overt assertion that precedes the sluiced question; in these cases, a 'what' question would count as answered by the antecedent if the correlate has a BL noun. What I suggest is that the same is true for SBL correlates: the sorts of contexts in which an antecedent

6 The property of objects denotation would clash with "what"s sortal restriction to kinds. 
with an SBL correlate would be relevantly informative are precisely those in which a subordinate level of specificity is not relevant. This has the effect of rendering the SBL of specificity salient, favoring the kinds reading over the sub-kinds reading.

(39) Specificity implicature: Given an assertion, A, in a discourse, D, with an inanimate SBL argument, A relevantly and completely addresses a 'what'question version of $\mathrm{A}$ in $\mathrm{D}$.

The implicature effectively blocks access to the sub-kinds reading with SBL nouns in sluicing contexts, so that, for instance, 'Jack ordered a Cajun dish' counts as an answer to the question 'what did Jack order?.' The sluiced question in (40), then, counts as answered, in violation of the Answer Ban, blocking sluicing.

* Jack ordered a Cajun dish, but Fred doesn't know what Jack orered.

As for how 'exactly'-modification of the remnant saves examples like (40), it is noted in D\&S that 'exactly'-modified Qs presuppose that a more precise answer is possible than some already-available answer in the discourse. This is an indication that 'exactly' cancels the implicature in (39), signaling that a more specific level is relevant. This gives access to the sub-kinds reading for the correlate, allowing Inheritance of Content to rescue what would otherwise be an Answer Ban violation.

Worth noting, is that there are other ways to render the sub-kinds interpretation salient and relevant in a given discourse. In the discourse in (41), the Question under Discussion (QuD), is about sub-kinds of Cajun dish; here, 'exactly'-modification becomes optional. This contextual manipulation essentially renders redeemable violations defiant, in support of the pragmatic account defended here.

A: Jack ordered jambalaya, Sally ordered gumbo, and Bill, étoufée.

B: What about Matt?

A: Well, Matt got a Cajun dish too, but I can't remember what (exactly).

\subsubsection{Sluicing with BL correlates (irredeemable violations)}

As shown above, the kind reading for an SBL noun gives a violation of the Answer Ban; the same is straightforwardly true for BL nouns. Since BL correlates lack a sub-kinds reading, needed to satisfy the Answer Ban, we predict that BL correlates yield unacceptable bare violations. Furthermore, 'exactly'-modification will fail since BL nouns lack a sub-kinds reading.

While BL nouns lack a sub-kinds reading in the cases we've examined so far, sub-basic level categories are conceptually available; we can easily imagine various sub-kinds of donut (see (42)). This raises the question of how such levels may be accessed in a discourse. Given the data we've examined so far, the pattern seems to be that BL nouns themselves consistently fail to make such a reading salient. We must resort to alternative mechanisms, such as the utterance context. 
Harmonic sluicing

(42)

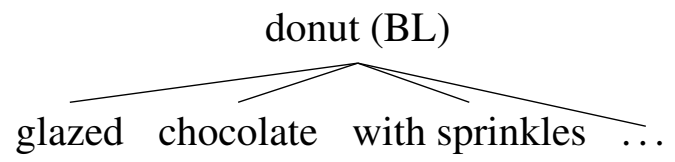

The lack of access to sub-basic levels with BL nouns is something I will not address to any satisfying notion of depth here, though I do point out that the question's presupposition is perhaps too strong. There are ways to manipulate examples that render sub-basic levels salient, though, there is reason to believe that such access does not come from the BL noun itself, but from other sources.

Recall that the analysis proposed here is concerned with providing an account for examples like those in (9-11). Such examples have a specific character: we have an antecedent followed by a sluiced 'what'-question; and the correlate in each case is a simple indefinite description. Sticking to these sorts of cases has been useful, in that they serve as a control which allows us to isolate the correlate's NP as the culprit behind what renders a given bare violation redeemable or irredeemable.

Once we consider different sorts of examples, the picture becomes muddied, as the redeemable/irredeemable distinction is blurred; under certain conditions, we can break the correlation between level of specificity and redeemability. Nonetheless, a case can be made that the account for the pattern in (9-11) proposed here extends to these other cases (the Answer Ban is behind the acceptability patterns we find).

There are other ways besides 'exactly'-modification of the remnant to access the sub-kinds reading for a given correlate. For instance, a sub-kinds reading can be explicitly constructed, with the ' $k$ ind of $N$ ' construction, which forces a sub-kinds reading (see Wilkinson 1995, Zamparelli 1998 and references).

a. Context: 3 bowls of gumbo, 3 of jambalaya, 3 of étouffée.

Count the kinds of Cajun dish on the table.

Possible answers: $3, * 9$. (only subkind)

b. Context: 3 chocolate donuts, 3 glazed, 3 with sprinkles.

Count the kinds of donut on the table.

Possible answers: 3, *9 (only sub-kind)

As expected, sluicing is also possible with ' $k i n d$ of $N$ ' correlates (or remnants). Example (44) shows that when the correlate explicitly has a sub-kinds reading, a bare $\mathrm{ACH}$ violations becomes acceptable, even with a BL head noun (example (44a) is arguably not an ACH violation, since 'what' has an NP complement, 'kind').

(44) a. Jack ordered a donut, but Fred doesn't know what kind (of donut). ${ }^{7}$

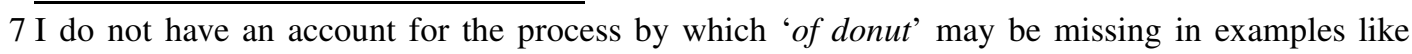


b. Sally ordered one of the kinds of donuts in the display case, but Fred couldn't remember what (exactly).

Aside from the ' $k i n d$ of $N$ ' construction, there are other ways to render subbasic level kinds salient. Context is important. By far, the majority of sluices in the literature involve simple examples with no context. Once context is provided, the empirical picture changes. Consider (45), below. In (45), a set of sub-kinds of a basic level category is made salient, unlocking access to a sub-kinds reading for speaker A's question (the remnant here is paraphrasable as 'what kind of donut?'). ${ }^{8}$

(45) A: Jack got a glazed donut, Bill, a plain donut, and Sally, a jelly-filled donut.

B: What about Frank?

A: He got a donut too, but I didn't see what (exactly).

To summarize, a simple indefinite description with a BL noun, as in the correlates in (9), is insufficient to render a property of sub-kinds salient, though there are other mechanisms which can achieve this. Worth emphasizing is that 'exactly'modification by itself is not such a mechanism; it works with SBL correlates because SBL nouns are inherently ambiguous, having a property of sub-kinds as a possible reading. While the implicature in (39) renders the kinds reading more salient for SBL nouns, 'exactly' can explicitly cancel (39), granting access to the sub-kinds reading. Since BL nouns lack a sub-kinds reading, 'exactly' won't help.

\subsection{Hyper level NPs}

$\mathrm{ACH}$ defiant correlates containing nouns like 'food,' 'appetizer,' 'drink,' are just like redeemable correlates in having a sub-kinds reading:

Jack detests several foods. (cf. ' $\{$ several Cajun dishes/\#several donuts $\}$ ')

Given that 'exactly'-modification of the remnant is not required to render an $\mathrm{ACH}$ violation acceptable in these cases, I assume that such nouns do not come with the

(44a); there is no such thing as PP ellipsis in English, though perhaps ' $o f$ ' in (44a) is inserted postsyntactically, maybe for Case reasons. NP ellipsis may obviate the need for the Case licensing preposition. Alternatively, a more general process like "predicate ellipsis" may be at work.

8 Sub-kinds readings may also be made salient outside of sluicing contexts. Consider, for instance, (ii); here 'the same donut' is most naturally paraphrased as 'the same kind of donut' (thanks to Cleo Condoravdi (p.c.) for this sort of example):

(ii) Every morning, on the way to work, Jack stops at the donut shop on the corner and always orders the same donut.

Characterizing all the ways a sub-kinds reading may be accessed with BL nouns is beyond the scope of this paper, though the reader should keep in mind that in the simple cases, it is not accessible. 
specificity implicature of SBL correlates. Thus, 'exactly'-modification would be unnecessary, as the sub-kinds reading is not suppressed.

Inheritance of Content, then, may target the sub-kinds reading, avoiding a violation of the Answer Ban (the antecedent does not entail Ans $(Q))$ :

Jack had some food for lunch, but I don't know what.

$\lambda \mathrm{p} \exists \mathrm{x}^{\mathrm{k}}\left[\right.$ non-human $\left(\mathrm{x}^{\mathrm{k}}\right) \wedge$ food $\left.{ }^{\text {sub-kinds }}\left(\mathrm{x}^{\mathrm{k}}\right) \wedge \mathrm{p}={ }^{\wedge} \exists \mathrm{y}^{\mathrm{o}}\left[\mathrm{x}^{\mathrm{k}}\left(\mathrm{y}^{\mathrm{o}}\right) \wedge \operatorname{had}\left(\mathrm{Jack}, \mathrm{y}^{\mathrm{o}}\right)\right]\right]$

$=\left\{\wedge \exists \mathrm{y}^{\mathrm{o}}\left[{ }^{\cup}\right.\right.$ Chinese food $\left.{ }^{\mathrm{k}}\left(\mathrm{y}^{\mathrm{o}}\right) \wedge \operatorname{had}\left(\mathrm{Jack}, \mathrm{y}^{\mathrm{o}}\right)\right]$,

$\left.\wedge \exists \mathrm{y}^{\mathrm{o}}\left[{ }^{\cup} \operatorname{Italian}^{\mathrm{k}}\left(\mathrm{y}^{\mathrm{o}}\right) \wedge \operatorname{had}\left(\operatorname{Jack}, \mathrm{y}^{\mathrm{o}}\right)\right], \ldots\right\}$

\section{Animate correlates}

Bare violations with 'who,' with animate indefinite descriptions as correlates are $\mathrm{ACH}$ defiant, as noted in D\&S. The level of specificity of the correlate is irrelevant:

Sally met with a $\{$ scientist/geologist/seismologist $\}$, but I don't know who.

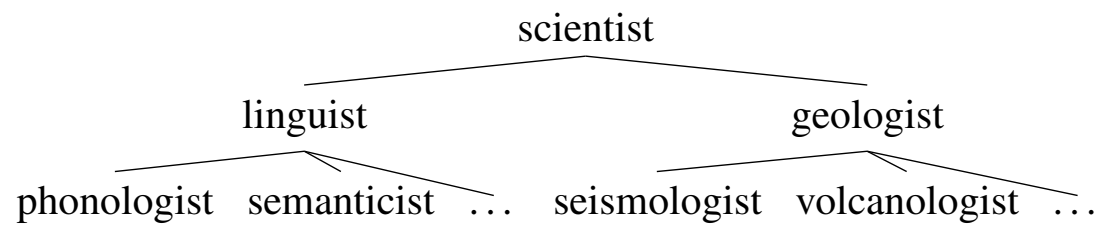

This pattern follows if the domain of quantification for 'who,' unlike 'what,' is not sortally restricted to kinds, but object level entities instead. Since NPs are ambiguous between denoting a property of objects or kinds, the property of objects would always be available for inheritance. Inheriting the property of objects as the restriction allows the antecedent/sluice pair to respect the Answer Ban (the antecedent in (49) would not entail Ans(Q), since no specific lawyer is entailed):

Jack met with a lawyer, but I don't know who.

$\lambda \mathrm{p} \exists \mathrm{x}^{\mathrm{o}}\left[\right.$ human $\left(\mathrm{x}^{\mathrm{o}}\right) \wedge$ lawyer ${ }^{\text {objects }}\left(\mathrm{x}^{\mathrm{o}}\right) \wedge \mathrm{p}={ }^{\wedge}$ met-with $\left(\right.$ Jack,, $\left.\left.\mathrm{x}^{\mathrm{o}}\right)\right]$

$=\left\{{ }^{\wedge}\right.$ met-with $($ Jack, lawyer Bill $)$,

$\wedge^{\wedge}$ met-with(Jack, lawyer Sally), ... \}

However, the empirical picture is not so clean, once again, if we deviate from indefinite descriptions as correlates. As noted in D\&S, examples like (50) require 'exactly'-modification of the remnant:

(50) Linguists go to those conferences, but I don't know who *(exactly).

I lack an account for why 'exactly'-modification is needed in these cases, but highlight some empirical observations that could be useful in formulating such an account. The fact that the antecedent in (50) is a generic sentence with a bare plural (kind denoting) correlate seems important, as either switching to an episodic (as in 
(51a)), or replacing the bare plural with a non-bare plural (as in (51b)) renders the example ACH defiant. The relationship between episodicity, bare plural correlates, and the Answer Ban is left for future work.

(51) a. Linguists were at the conference last week, but I don't know who.

b. Some linguists go to those conferences, but I don't know who.

\section{The Answer Ban and Inheritance of Content}

I now shift the focus from ACH to the Answer Ban. I show how the Answer Ban fills a gap in Romero's (1998) account of Inheritance of Content. Romero's (1998) claim is that Inheritance of Content is a direct consequence of conditions on focus and deaccenting in Rooth 1992a, Rooth 1992b; Schwarzschild 1999. For space reasons, I do not discuss the account in Romero 1998 in its entirety, and instead focus on a subset of cases where Romero's account overgenerates.

Inheritance of Content is satisfied when the domain of quantification of the correlate and the remnant are equivalent, which follows straightforwardly if Inheritance of Content is when the domain of the remnant is restricted by the correlate's property. Inheritance of Content is not satisfied whenever the correlate/remnant's respective domains of quantification are in a (proper) subset to superset, or disjoint relation (i.e. when domain restriction of the remnant by the correlate's descriptive content does not obtain). The crucial case for our purposes is when the correlate's domain of quantification is a proper subset of that of the remnant.

In Romero's (1998) theory, inheritance of content follows from non-sluicingspecific conditions on the licensing of prosodic reduction. However, Romero (1998) notes that while these conditions are met in subset to superset cases, Inheritance of Content is still detectible. In (52), the sluiced Q is about students, not people:

Jack talked to some students, but I don't know who.

a. $=\ldots$ but I don't know who (students) he talked to.

b. $\neq \ldots$. but I don't know who (people) he talked to.

In Romero's (1998) account, the antecedent must entail the presupposition of the sluiced Q. ${ }^{9}$ In a subset to superset violation of Inheritance of Content, as in (52b), the antecedent entails the presupposition of the sluice ('Jack talked to someone'). Though the conditions on focus/deaccenting are met, sluicing is still out.

To remedy this, Romero (1998) appeals to Q-felicity conditions; (52b) is inconsistent since the speaker is committed to knowing a (partial) answer to the sluiced

9 This is a (perhaps over-) simplification of Rooth's and Schwarzschild's respective machineries as implemented in Romero 1998, but it will do for our purposes. The reader is invited to check that this move is harmless. 
question by uttering the antecedent and cannot then deny knowledge of Q. ${ }^{10}$ As with the argumentation in D\&S in favor of treating $\mathrm{ACH}$ as 'sluicing-specific' (see $\S 2.1$ ), this hypothesis predicts that switching the subject of the matrix clause from $1^{s t}$ to $3^{r d}$ person should free us from Inheritance of Content effects, as Q-felicity conditions would be satisfied. However, Inheritance of Content persists even with this manipulation, supporting a sluicing-specific account.

Jack talked to some students, but Fred doesn't know who.

a. $=\ldots$ but Fred doesn't know who (students) he talked to.

b. $\neq \ldots$ but Fred doesn't know who (people) he talked to.

Of course, the Answer Ban is sluicing-specific and explains the pattern in (53): sluicing is out with interpretation (53b), since the antecedent is a partial answer to the sluiced Q. A simple definition of partial answers suffices for our purposes; intuitively, we want propositions that remove from consideration a subset of propositions in $\llbracket \mathrm{Q} \rrbracket$ to count as partial answers. The antecedent in (53) meets this criterion as it removes propositions where Jack did not talk to a student. The antecedent in (53) counts as a partial answer to the unrestricted (53b), but not (53a). The Answer Ban acts as a sort of filter on possible interpretations for a sluice, as only the interpretation consistent with domain restriction renders the antecedent a non-answer.

\section{Deriving the Answer Ban}

The claim in D\&S is that $\mathrm{ACH}$ follows from a semantic licensing condition on sluicing. Since I am arguing that (sluicing-specific) ACH follows from the Answer Ban, it is the Answer Ban that should be derived. I show how the Answer Ban follows automatically from the inquisitive semantic proposal in AnderBois 2011.

In inquisitive semantics, a sentence, $S$, may be informative, inquisitive, or both (called hybrid sentences). Sentences with indefinites and disjunctions (which make good antecedents) count as hybrid. Inquisitive Ss denote sets of alternatives (called possibilities) (written [S]), and raise an issue as to which alternative is the case. For instance, the sentence 'Jack or Sally left' raises the issue of whether Jack, Sally, or both left. The informative contribution of the sentence in a discourse is equivalent to its classical meaning, and proposes to update the context by excluding worlds where neither Jack nor Sally left.

Given two sentences, $S_{1}$ and $S_{2}, S_{1}$ partially addresses an issue raised by $S_{2}$ if $S_{1}$ 's informative contribution removes a proper subset of possibilities in $S_{2}$ from

10 As a side note, Romero 1998 claims that 'exactly'-modification of the remnant can circumvent this, as there is no commitment on the part of the speaker for knowing 'exactly-Q.' However, as far as I can tell, the Inheritance of Content facts persist in (52b), even under 'exactly'-modification, providing an empirical puzzle for her account. 
consideration, and completely addresses it if it also picks out a unique possibility in $\mathrm{S}_{2}$. A hybrid assertion cannot address an issue it, itself, raises. This can be shown with a hybrid sentence, S, with an indefinite description. The choice of NP in the indefinite serves an 'issue-regulating' role, in that its contribution to the informative content of S precludes certain possibilities from [S]. Another way of stating this is that $\mathrm{S}$ can, at best, only address broader issues than any that it introduces.

Consider the sentence 'Jack met a student'; [S] would be a set of alternatives differing with respect to distinct students Jack might have met, since the informative content of the sentence removes from consideration possibilities where Jack did not meet a student. S, here, can only be seen as partially addressing a broader issue; the issue of who he met more generally, and it says that whoever it was was a student.

In the theory of AnderBois 2011, sluicing may go through only if the antecedent and sluice raise the same issues (i.e. the sets of possibilities associated with each are mutually entailing). Since a hybrid assertion (e.g. a sluicing antecedent) cannot address the issue it raises, if the issue it raises is to be equivalent to that raised by a subsequent sluice, then it cannot address the issue raised by the sluice either.

\section{Conclusion}

Conceptually, the approach adopted here is a reductionist one, in that it takes two generalizations in the literature, $\mathrm{ACH}$ and the Answer Ban, and derives them from independent properties of sluices. As a generalization, $\mathrm{ACH}$ itself (even sluicingspecific $\mathrm{ACH}$ ) is too strong as it stands, though the counterexamples (acceptable violations) are shown to follow from how the semantics of questions and antecedents interact with a more robust sluicing-specific generalization, the Answer Ban.

An empirical contribution of this work is the three way split between BL, SBL, and HL nouns, which not only finds independent support outside of sluicing, but gives us a handle on bare $\mathrm{ACH}$ violation acceptability patterns. The semantics of remnants and correlate NPs, specifically, the animate/inanimate distinction, and whether the correlate's head noun counts as BL, SBL, or HL, play a central role in determining whether a sluice violates the Answer Ban. Inheritance of Content, pace Romero (1998), was shown to count as yet another sluicing-specific generalization, luckily one which could also be collapsed with the Answer Ban.

The Answer Ban, was, in turn, argued to follow from a sluicing-specific semantic identity condition, something which is uncontroversially independently needed. As noted in Chung 2013, there is no consensus as to what that condition is, though there are many proposals on the market. The approach adopted here is that of AnderBois 2011, in large part because that theory automatically yields the Answer Ban straightforwardly as a consequence. Whether other theories, such as that of Merchant 2001, give similar results is left as a project for future work. 
Harmonic sluicing

\section{References}

AnderBois, Scott. 2011. Issues and Alternatives: UC Santa Cruz dissertation.

Bach, Emmon \& Robin Cooper. 1978. The NP-S analysis of relative clauses and compositional semantics. Linguistics and Philosophy 2. 145-150.

Barker, Chris. in press. Scopability and sluicing.

Brown, Roger. 1958. How shall things be called? Psychological Review 65(1). $14-21$.

Chierchia, Gennaro. 1998. Reference to kinds across languages. Natural Language Semantics 6. 339-405.

Chung, Sandra. 2013. Syntactic identity in sluicing: How much and why. Linguistic Inquiry 44(1). 1-44.

Chung, Sandra, William Ladusaw \& James McCloskey. 1995. Sluicing and logical form. Natural Language Semantics 3. 239-282.

Cruse, D. Alan. 1977. The pragmatics of lexical specificity. Journal of Linguistics 13. 153-164.

Dayal, Veneeta. 1996. Locality in Wh Quantification: Questions and Relative Clauses in Hindi. Kluwer Academic Publishers.

Dayal, Veneeta. 1997. Free relatives and ever: Identity and free choice readings. In Aaron Lawson (ed.), Semantics and Linguistic Theory (SALT) VII, vol. VII, 99-116. Ithaca, NY: Cornell University.

Dayal, Veneeta. 2004. Number marking and (in)definites in kind terms. Linguistics and Philosophy 27. 393-450.

Dayal, Veneeta \& Roger Schwarzschild. 2010. Definite inner antecedents and whcorrelates in sluicing. In Peter Staroverov, Aaron Braver, Daniel Altshuler, Carlos Fasola \& Sarah Murray (eds.), Rutgers Working Papers in Linguistics, vol. 3, 92-114. New Brunswick, NJ: LGSA.

Groenendijk, Jeroen \& Floris Roelofsen. 2009. Inquisitive semantics and pragmatics. In Ms. Larraitz Zubeldia \& Jesus Larrazabal (eds.), Semantics Pragmatics and Rhetoric (SPR) 09, Donostia, Spain.

Hamblin, C. L. 1973. Questions in Montague English. Foundations of Language 10. 41-53.

Hankamer, Jorge \& Ivan Sag. 1976. Deep and surface anaphora. Linguistic Inquiry 7. 391-428.

Heim, Irene. 1987. Where does the definiteness restriction apply? In Eric Reuland $\&$ Alice ter Meulen (eds.), The representation of (in)definiteness, Cambridge, Massachusetts: MIT Press.

Heim, Irene \& Angelika Kratzer. 1998. Semantics in Generative Grammar. Blackwell Publishing.

Heller, Daphna \& Lynsey Wolter. 2008. Identity and indeterminacy in -ever free 
relatives. In Atle Grønn (ed.), Sinn und Bedeutung (SuB) 12, vol. 18, 226-240. Amherst, MA.

Karttunen, Lauri. 1977. Syntax and semantics of questions. Linguistics and Philosophy 1.3-44.

Krifka, Manfred, Francis Jeffry Pelletier, Gregory N. Carlson, Alice ter Meulen, Godehard Link \& Gennaro Chierchia. 1995. Genericity: An Introduction. In Greg Carlson \& Francis Jeffry Pelletier (eds.), The Generic Book, 1-124. Chicago, London: University of Chicago Press.

Merchant, Jason. 2001. The Syntax of Silence: Sluicing, Islands, and the Theory of Ellipsis. Oxford: Oxford University Press.

Milsark, Gary. 1977. Toward an explanation of certain peculiarities of the existential construction in English. Linguistic Analysis 3. 1-29.

Roberts, Craige. 1996. Information structure: Towards an integrated theory of formal pragmatics. In Jae-Hak Yoon \& Andreas Kathol (eds.), OSU Working Papers in Linguistics, vol. 49, OSU: The Ohio State University Department of Linguistics.

Romero, Maribel. 1998. Focus and Reconstruction Effects in Wh-phrases: University of Massachusetts Amherst dissertation.

Rooth, Mats. 1992a. Ellipsis redundancy and reduction redundancy. In Steve Berman \& Arild Hestvik (eds.), Stuttgart ellipsis workshop, Arbeitspapiere des Sonderforschungsbereichs 340, Germany, Heidelberg.

Rooth, Mats. 1992b. A theory of focus interpretation. Natural Language Semantics 1. 75-116.

Rosch, Eleanor. 1978. Principles of categorization. In Eleanor Rosch \& Barbara Lloyds (eds.), Cognition and Categorization, NJ: Erlbaum: Hillsdale.

Rosch, Eleanor, Carolyn Mervis, Wayne Gray, David Johnson \& Penny BoyesBraem. 1976. Basic objects in natural categories. Cognitive Psychology 8. 382-439.

Ross, John. 1969. Guess who? In Robert Binnick, Alice Davison, Georgia Green \& Jerry Morgan (eds.), Chicago Linguistic Society (CLS) 5, 252-286. University of Chicago, Chicago, Illinois: Chicago Linguistic Society.

Schwarzschild, Roger. 1999. GIVENness, AvoidF, and other constraints on the placement of accent. Natural Language Semantics 7. 141-177.

von Fintel, Kai. 1994. Restrictions on Quantifier Domains: University of Massachusetts at Amherst dissertation.

Wilkinson, Karina. 1995. The semantics of the common noun kind. In Greg Carlson \& Francis Jeffry Pelletier (eds.), The Generic Book, 383-397. Chicago, London: University of Chicago Press.

Zamparelli, Roberto. 1998. A theory of kinds, partitives and of/z possessives. In Artemis Alexiadou \& Chris Wilder (eds.), Possessors, Predicates and Move- 
Harmonic sluicing

ment in the Determiner Phrase (Linguistics Today 22), John Benjamins.

Matthew Barros

Department of Linguistics

Rutgers, The State University of New Jersey

18 Seminary Place

New Brunswick, NJ 08901

mattbarros@gmail.com 